\title{
Photoelectrode for water splitting: Materials, fabrication and characterization
}

\author{
Zhiliang Wang and Lianzhou Wang*
}

\begin{abstract}
Photoelectorchemical (PEC) water splitting is an attractive approach for producing sustainable and environment-friendly hydrogen. An efficient PEC process is rooted in appropriate semiconductor materials, which should possess small bandgap to ensure wide light harvest, facile charge separation to allow the generated photocharges migrating to the reactive sites and highly catalytic capability to fully utilize the separated photocharges. Proper electrode fabrication method is of equal importance for promoting charge transfer and accelerating surface reactions in the electrodes. Moreover, powerful characterization method can shed light on the complex PEC process and provide deep understanding of the rate-determining step for us to improve the PEC systems further. Targeting on high solar conversion efficiency, here we provide a review on the development of PEC water splitting in the aspect of materials exploring, fabrication method and characterization. It is expected to provide some fundamental insight of PEC and inspire the design of more effective PEC systems.
\end{abstract}

Keywords: photoelectrode, water splitting, semiconductor material, electrode fabrication, characterization

\section{INTRODUCTION}

Solar energy is a dreaming source because it is abundant and environmentally benign. The sunlight irradiation received by earth is $1.7 \times 10^{14} \mathrm{~J}$ in one second, which is far more than the total energy consumption by human in one year $[1,2]$. Therefore, converting the solar energy into valuable fuels or electricity will be very appealing and important for decreasing the dependence on fossil fuel. Photoelectrochemistry (PEC) represents a promising method for solar energy conversion.

PEC process has many advantages over other solar conversion methods (e.g., solar-thermal conversion, solar cell), such as high solar conversion efficiency due to the application of external bias, portable product for the stored energy [3-5]. The fundamentals and concept of PEC have been well developed in 1970s, based on which the dye-sensitized solar cell (DSSC) and PEC water splitting are stimulated by the energy crisis during the 1970-1980s [6-11]. Ever since, many researchers have made great efforts to promote the PEC solar production, especially the PEC water splitting for $\mathrm{H}_{2}$ production, targeting a solar-to-hydrogen (STH) efficiency of $10 \%$ for commercial application [12-14].

The development of PEC water splitting relies on the progress of advanced materials exploring. The ideal candidate should have a wide range of light absorption, facile surface reaction kinetics and high stability under operating condition [15-17]. Unfortunately, there is no single semiconductor meeting all the requirements until now. On the other hand, suitable electrode fabrication method is of equal importance for PEC because it may determine the charge transfer through the whole photoelectrode [18]. And the electrode fabrication method depends on the property and preparation of the semiconductor itself. Moreover, advanced characterization method can help us deeply understand the PEC water splitting system and figure out the rate-determining steps, which can inspire researchers to explore more effective PEC system. There have been many excellent researches focusing on each of the topics [15-18], but a timely review to take all the aspects about PEC process into consideration is still lacking. Herein, we focus on the materials exploring, electrode fabrication method and characterization method to summarize the development of PEC water splitting progress which have not been

School of Chemical Engineering and Australian Institute for Bioengineering and Nanotechnology, The University of Queensland, St Lucia, QLD 4072, Australia

* Corresponding author (email: 1.wang@uq.edu.au) 
addressed in much details in literature. It is expected that this review may provide some guidance and inspiration on designing and characterizing new and efficient PEC water splitting system.

\section{FUNDAMENTALS OF PEC PROCESS}

The PEC process occurred at the interface of semiconductor/electrolyte composed of a space charge layer of the semiconductor and the adjacent Helmholtz layer of the electrolyte $[7,10]$. For the semiconductor, the Fermi level $\left(E_{\mathrm{F}}\right)$ and band gap $\left(E_{\mathrm{g}}\right)$ are determined by the conduction band $(\mathrm{CB})$ and valance band (VB). As photoelectrode, either holes or electrons will be drifted via the conductive substrate, leaving only one kind of charge carrier for surface PEC reaction [8]. Especially, for n-type semiconductor, the holes are left and accumulated on the surface space charge layer, leading to a possible oxidative reaction. And for the p-type semiconductor, the reductive reaction is expected. Since the driving force of the reaction is provided by the band bending (originating from the $E_{\mathrm{F}}$ difference between semiconductor and electrolyte) $[8,19]$, the flatted band of $\mathrm{CB}$ and VB will thermodynamically determine the reductive and oxidative reaction happening on the surface, respectively [7]. The band structure of some commonly used PEC semiconductors are summarized in Fig. 1 in comparison with the standard redox potential of the hydrogen evolution reaction (HER) and oxygen evolution reaction (OER). Taking the $\mathrm{TiO}_{2}$ for example, its $\mathrm{CB}$ and $\mathrm{VB}$ lay at -0.2 and $3 \mathrm{~V}$ vs. RHE respectively, which straddle the oxidative potential of $\mathrm{H}^{+}$/ $\mathrm{H}_{2}$ and the reductive potential of $\mathrm{H}_{2} \mathrm{O} / \mathrm{O}_{2}$, as confirmed in literature $[6,20,21]$.

Besides the thermodynamic requirement, the PEC reaction also needs to fulfill some kinetic criteria. It has reached a consensus that the PEC process has at least three key steps to utilize the solar energy, which are light harvest, charge separation and surface reaction as shown in Fig. 2, determined by the bulk and surface properties of the semiconductor $[22,23]$. For the light harvest of an electrode, the efficiency $\left(\eta_{\mathrm{LH}}\right)$ depends on the absorbance of the semiconductor which usually has close relationship with the bandgap of the semiconductor, transition model (direct or indirect transition), film thickness, etc. [24]. Based on $\eta_{\mathrm{LH}}$, the utmost photocurrent $\left(j_{\text {abs }}\right)$ that one photoelectrode can achieve can be calculated by integrating the light harvest efficiency and flux of sunlight (I, Equation (1)). Especially, with the assumption that the $\eta_{\mathrm{LH}}$ of photons with energy higher than $E_{\mathrm{g}}$ is unit and photons with energy lower than $E_{\mathrm{g}}$ is null, the theoretical photoresponse $\left(j_{\mathrm{ph}}\right)$ of a semiconductor can be evaluated

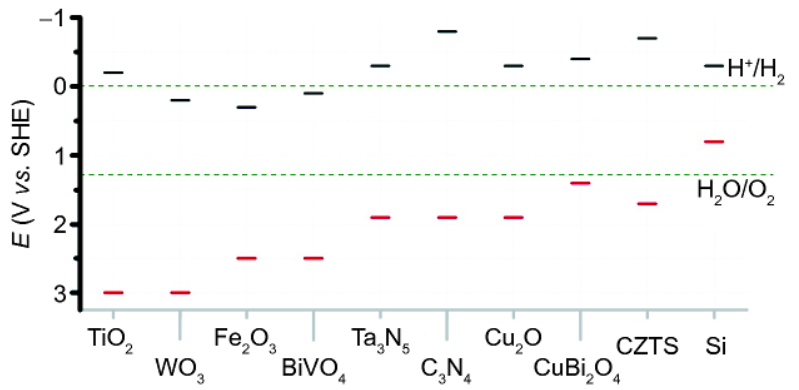

Figure 1 The band structure of selected semiconductors, CZTS: $\mathrm{CuZnSnS}_{4}$.

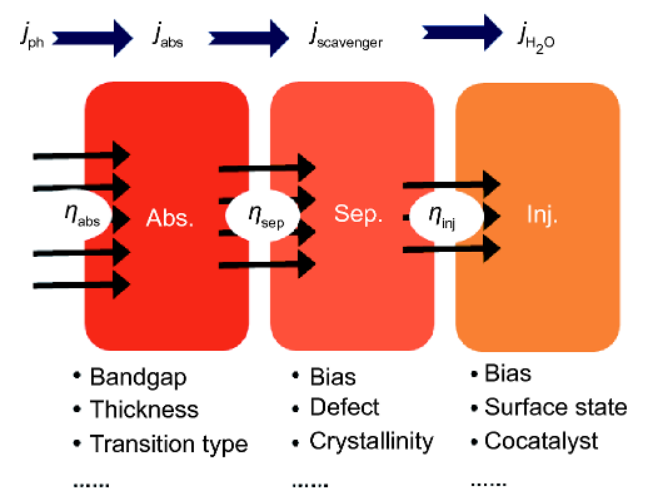

Figure 2 The schematic illustration of the PEC processes and the related influence factor of each step.

according to the $E_{\mathrm{g}}$ of the semiconductor $[7,24]$. However, the practical photoresponse $(j)$ is often lower than the $j_{\text {abs }}$ and $j_{\mathrm{ph}}$ due to the recombination of the photon-generated electrons and holes via the recombination centres. The charge separation efficiency $\left(\eta_{\text {sep }}\right)$ can be used to evaluate the survived photocharges for further surface reaction. It is determined by the built-in field potential $\left(E_{\mathrm{bi}}\right)$ in the semiconductor principally, so the criteria influencing the magnitude of $E_{\mathrm{bi}}$, such as intermediate energy level $\left(E_{\mathrm{i}}\right)$, defect state, applied bias, crystallinity, will largely affect the $\eta_{\text {sep }}$ [25]. Despite of the simple understanding of charge separation, the $\eta_{\text {sep }}$ indeed varies at different moment during the PEC process, especially when considering the recombination process during the charge exchange between semiconductor and electrolyte. In order to make the $\eta_{\text {sep }}$ a measureable parameter, it is specially referred to the process before the semiconductorelectrolyte charge transfer occurs. In this consideration, the $\eta_{\text {sep }}$ can be evaluated with the $j_{\text {abs }}$ and the photocurrent $\left(j_{\text {scavenger }}\right)$ measured with the existence of hole or electron scavenger (e.g., $\mathrm{H}_{2} \mathrm{O}_{2}, \mathrm{Fe}(\mathrm{CN})_{6}{ }^{4-/ 3-}$ ) to remove the surface reaction barrier and suppress the surface charge re- 
combination according to Equation (2) [22]. While for the continuous step of surface reaction, due to the limited reaction kinetics, many separated charges cannot be effectively used for water splitting and the ratio of consumed charges $\left(j_{\mathrm{H}_{2} \mathrm{O}}\right)$ over the whole survived ones transferring to the surface $\left(j_{\text {scavenger }}\right)$ is defined as charge injection efficiency $\left(\eta_{\text {inj }}\right.$, Equation (3)). The $\eta_{\text {inj }}$ is usually impacted by factors such as surface states and compositions.

$$
\begin{gathered}
j_{\text {abs }}=\int \eta_{\mathrm{LH}}(\lambda) I(\lambda) \mathrm{d} \lambda=j_{\mathrm{ph}} \eta_{\mathrm{LH}}, \\
j_{\text {scavenger }}=j_{\text {abs }} \eta_{\text {sep }}, \\
j_{\mathrm{H}_{2} \mathrm{O}}=j_{\text {scavenger }} \eta_{\text {inj. }} .
\end{gathered}
$$

According to the above discussion, the practical photoresponse $(j)$ is the production of the theoretical photocurrent $\left(j_{\mathrm{ph}}\right)$, light harvest efficiency $\left(\eta_{\mathrm{LH}}\right)$, charge separation efficiency $\left(\eta_{\text {sep }}\right)$ and surface charge injection efficiency $\left(\eta_{\text {inj }}\right)$ (Equation (4)). And all the efforts are aiming at addressing the limitation of these factors for achieving high photocurrent. However, it is not an easy task because these steps interact with each other and we have to balance every step when we try an optimization. For example, in $\mathrm{WO}_{3}$ photoanode, the light absorption efficiency can be improved via a reductive treatment [2628]. But as a trade-off, the charge separation efficiency is greatly deteriorated due to the presence of $\mathrm{W}^{5+}$ intermediate.

$$
j=j_{\mathrm{ph}} \eta_{\mathrm{LH}} \eta_{\mathrm{sep}} \eta_{\mathrm{inj}}
$$

As the most important application of PEC, solar water splitting for hydrogen production has aroused worldwide attention for over four decades since the first report by Fujishima and Honda [6] . Many exciting progresses have achieved in the aspect of materials development, electrode fabrication methods, characterization and the solar conversion efficiency. Herein we will give a brief introduction according to some typical examples.

\section{MATERIALS FOR PEC WATER SPLITTING} Semiconductor materials are the indispensable foundations of the PEC water splitting and the breakthrough in materials always stimulates the progress of PEC research because it may open a new possibility for achieving higher solar conversion efficiency. Many kinds of semiconductors have been reported in literature and based on the cations in the crystal, they can be categorized into metal oxide, nitride, chacogenide, etc. In the following parts, they will be critically summarized according to some typical semiconductors.

\section{Metal oxides}

At the early stage of PEC research, the materials are just limited to some metal oxides, such as $\mathrm{TiO}_{2}[6,29], \mathrm{Fe}_{2} \mathrm{O}_{3}$ [30], $\mathrm{ZnO}$ [31], $\mathrm{WO}_{3}$ [32], etc. due to the issue of stability of other semiconductors [33]. Among various metal oxides, $\mathrm{BiVO}_{4}$ has appealed most of the attention ever since it was first reported by Kudo's group [34]. It has a bandgap of $2.4 \mathrm{eV}$ with a promising photocurrent over $7.4 \mathrm{~mA} \mathrm{~cm}^{-2}$ under $100 \mathrm{~mW} \mathrm{~cm}{ }^{-2}$ sunlight (AM 1.5G) [5]. Wang's group reported that the electrochemical reductive treatment can profoundly improve the photocurrent to $2.5 \mathrm{~mA} \mathrm{~cm}^{-2}$, [35] which is almost 10 times higher than the pristine one. Another breakthrough from Domen's group demonstrated that the stability of $\mathrm{BiVO}_{4}$ can excess $1,000 \mathrm{~h}$ under operation with the presence of in-situ generated nickel based oxygen-evolution cocatalyst [36]. However, the $\mathrm{BiVO}_{4}$ based PEC still faces the limitation of relatively large bandgap for the further practical application, which requires a solar conversion efficiency over $10 \%$.

Alternatively, $\mathrm{Fe}_{2} \mathrm{O}_{3}$ is regard as an attractive candidate for solar fuel production considering that it is very cheap, robust and the light absorption threshold of $600 \mathrm{~nm}$ promising over $10 \%$ solar conversion efficiency $[37,38]$. But this tough metal oxide has many limitations in terms of carrier diffusion, surface reaction, and so on. Research from Grätzel's group $[39,40]$ claimed that the cauliflower like hematite electrode with many small crystals aligned was the champion structure for charge transfer, leading to a photocurrent over $3 \mathrm{~mA} \mathrm{~cm}$. Furthermore, Peerakiatkhajohn et al. [41] reported a nanosheet structured hematite could reach a photocurrent of $4.68 \mathrm{~mA} \mathrm{~cm}^{-2}$ after modifying with $\mathrm{Ag}$ nanoparticles to facilitate the charge separation and CoPi to release the surface reaction (Fig. 3). From these efforts, it is believed that the hematite based PEC could obtain higher and higher solar conversion efficiency if suitable strategies can be applied to addressing the sluggish charge separation and transfer in the bulk and charge injection on the surface.

Most metal oxides are n-type semiconductors due to the presence of oxygen vacancy except the $\mathrm{Cu}_{2} \mathrm{O}$ which is a p-type semiconductor that can be used as the photocathode for water reduction. Its small bandgap (about $2 \mathrm{eV}$ ) promises an efficiency similar to hematite, but the redox potential of $\mathrm{Cu}_{2} \mathrm{O}$ makes it unstable with the presence of electrons or holes [42]. Paracchino et al. [43] found that the $\mathrm{Cu}_{2} \mathrm{O}$ photocathode can be stabilized after coating with monolayer $\mathrm{Al}$-doped $\mathrm{ZnO}$ and $\mathrm{TiO}_{2}$. But this relies on expensive equipment (atomic layer deposition) which limits its application in practice. And some other 
a
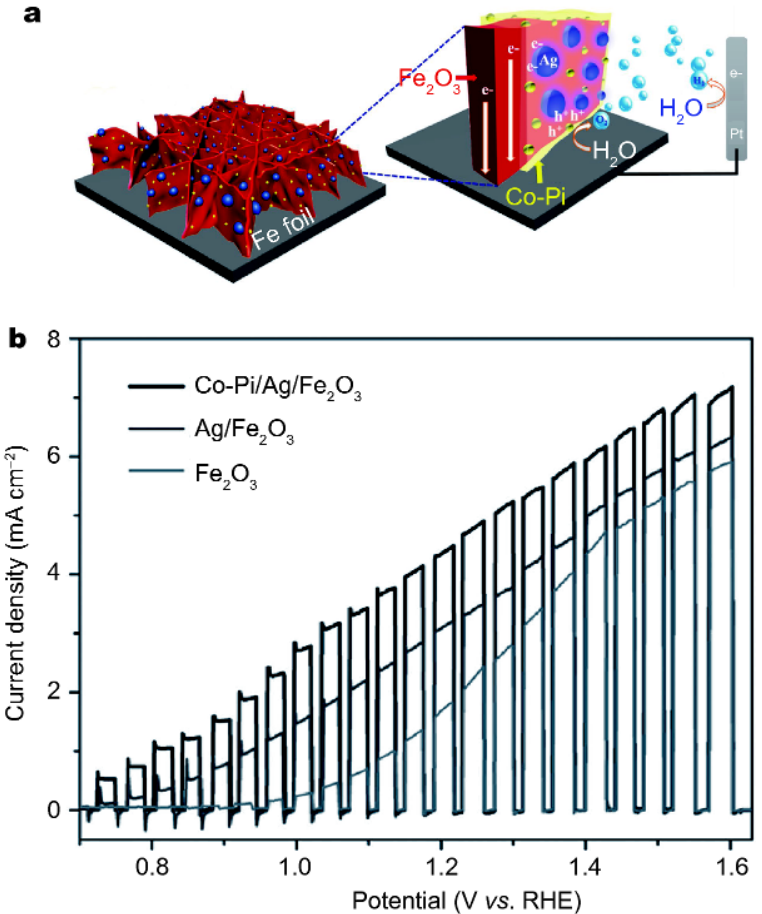

Figure 3 (a) The schematic illustration of Ag decorated $\mathrm{Fe}_{2} \mathrm{O}_{3}$ nanoflakes with $\mathrm{CoPi}$ as cocatalyst. (b) The photocurrent of different $\mathrm{Fe}_{2} \mathrm{O}_{3}$ electrode measured under $100 \mathrm{~W} \mathrm{~cm}^{-2}$ simulated sunlight (AM 1.5G). Reprinted with permission from Ref. [41]. Copyright 2016, John Wiley \& Sons, Inc.

$\mathrm{Cu}$ based semiconductors, such as $\mathrm{CuRuO}_{2}[44], \mathrm{CuBi}_{2} \mathrm{O}_{4}$ $[45,46]$, are found to give a photocatholic response with higher stability. However, the magnitude of photocurrent cannot be comparable with that of $\mathrm{Cu}_{2} \mathrm{O}$ which still needs more efforts to broaden light absorption.

Based on the above discussion, it indicates that the metal oxide based semiconductors possess the advantage of relatively facile and economic materials preparation methods. But their performance is still an challenge when aiming at the potential commercial utilization.

\section{Nitride and chalcogenides}

There are only limited kinds of visible light responsive metal oxide semiconductors that can be used for PEC research. The appearance of nitride (including oxynitride) and chalcogenide semiconductors greatly enlarges the available candidate for solar water splitting [47,48]. Due to the relatively smaller electronic negativity and lower orbital level, when $\mathrm{N}$ or $\mathrm{S}$ replaces the $\mathrm{O}$ during the nitridization or sulfurization, the VB will move upwards owning to the contribution of $\mathrm{N} 2 \mathrm{p}$ or S $2 \mathrm{p}$ orbital to the $\mathrm{VB}$, while $\mathrm{CB}$ that is composed of metal atomic orbital has little change, as a result of which the $E_{\mathrm{g}}$ decreases

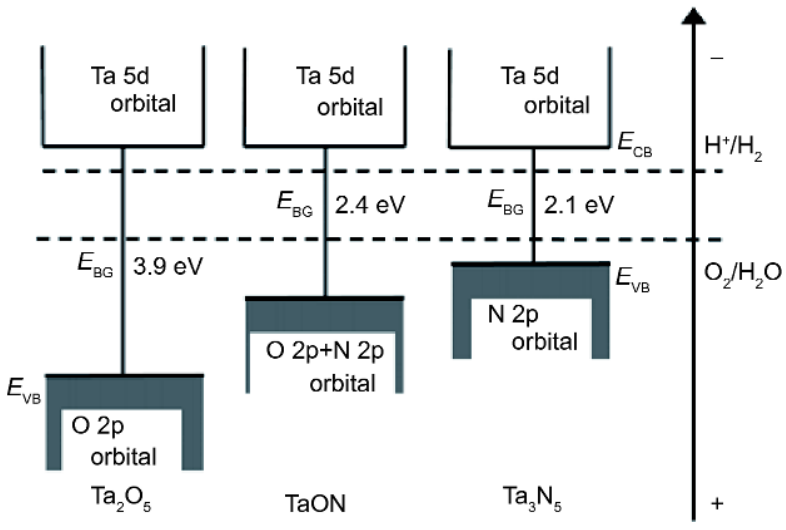

Figure 4 The band structure change when $N 2 p$ replaces $O 2 p$ orbital step by step. Reprinted with permission from Ref. [49]. Copyright 2003, American Chemical Society.

profoundly. For example, Fig. 4 indicates that when partially replacing the oxygen with $\mathrm{N}$ in $\mathrm{Ta}_{2} \mathrm{O}_{5}$ to form $\mathrm{TaON}$, the bandgap decreases to $2.4 \mathrm{eV}$ from $3.9 \mathrm{eV}$. If the $\mathrm{O}$ is totally replaced by $\mathrm{N}$, it will produce $\mathrm{Ta}_{3} \mathrm{~N}_{5}$ with a bandgap of $2.1 \mathrm{eV}$ [49], which is highly desired for PEC conversion considering the corresponding solar conversion efficiency of $16 \%$ [12].

The state-of-the-art photocurrent of $\mathrm{Ta}_{3} \mathrm{~N}_{5}$ has been reported to be $12 \mathrm{~mA} \mathrm{~cm}^{-2}$, suggesting the outstanding optoelectronic property of $\mathrm{Ta}_{3} \mathrm{~N}_{5}$ semiconductor [50]. In the $\mathrm{Ta}_{3} \mathrm{~N}_{5}$ electrode, $\mathrm{TiO}_{2}$ was deposited to block back electron-hole recombination, while ferrihydrate was used to capture holes for the further catalytic reaction on the molecular catalyst (Fig. 5). The near theoretical photocurrent suggests that artificial photosynthesis system has the possibility to approach high efficiency in the simulation. Other examples such as $\mathrm{CsTaWO}_{6}, \mathrm{Ba}_{2} \mathrm{Ta}_{2} \mathrm{O}_{7}$, $\mathrm{ZnGa}_{2} \mathrm{O}_{4}$, all have red-shift of their band edge upon nitridizing treatment, giving rise to $\mathrm{BaTaO}_{2} \mathrm{~N}, \mathrm{ZnGaON}$, etc. [51-54] with enhanced photocurrent. However, narrowing the bandgap is at the cost of weakening the oxidation potential because the potential difference between VB and $E_{\text {redox }}$ is decreased. Therefore, these nitride photoelectrodes usually have sluggish surface reaction and suitable cocatalyst is necessary for achieving high photoresponse.

Besides the nitride, chalcogenide is also a kind of good candidates for PEC considering that many of them have been applied in heterojunction solar cells, such as CuIn$\mathrm{GaSe}_{2}$ [55], $\mathrm{CuZnSnS}_{4}$ [56], CdSe [57], etc. For example, $\mathrm{CuZnSnS}_{4}$ has been demonstrated to possess a photocurrent over $8 \mathrm{~mA} \mathrm{~cm}^{-2}$ at $0 \mathrm{~V} v s$. RHE upon modifying with $\mathrm{CdS} / \mathrm{In}_{2} \mathrm{~S}_{3} / \mathrm{Pt}$ [56]. But the stability of chalcogenide is 

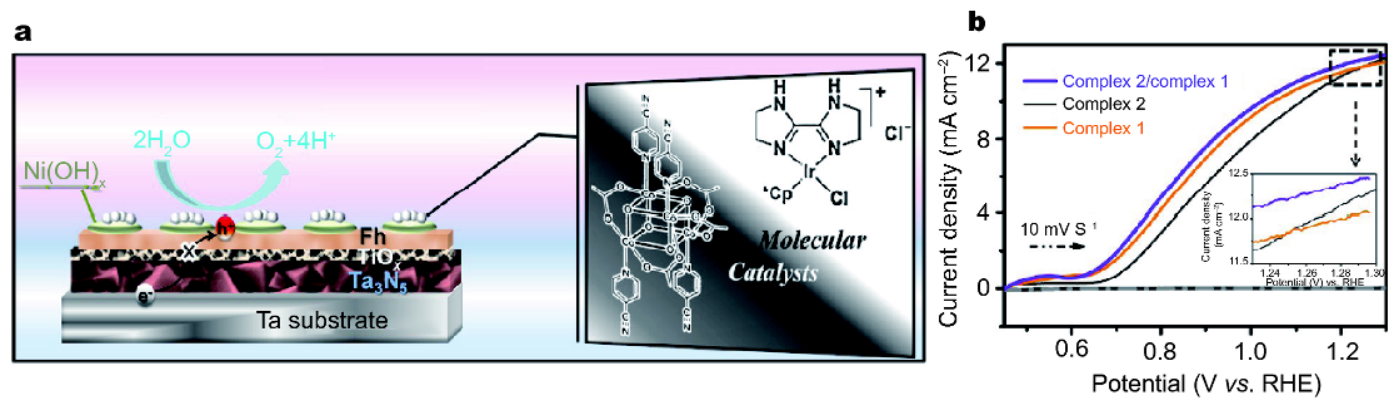

Figure 5 (a) The schematic illustration of $\mathrm{Ta}_{3} \mathrm{~N}_{5} / \mathrm{TiO}_{2} /$ ferrihydrate/molecular catalyst photoelectrode. (b) The photocurrent of different $\mathrm{Ta}_{3} \mathrm{~N}_{5}$ photoelectrode measured under $100 \mathrm{~mW} \mathrm{~cm}^{-2}$ simulated sunlight (AM 1.5G). Reprinted with permission from Ref. [50]. Copyright 2016, the Royal Society of Chemistry.
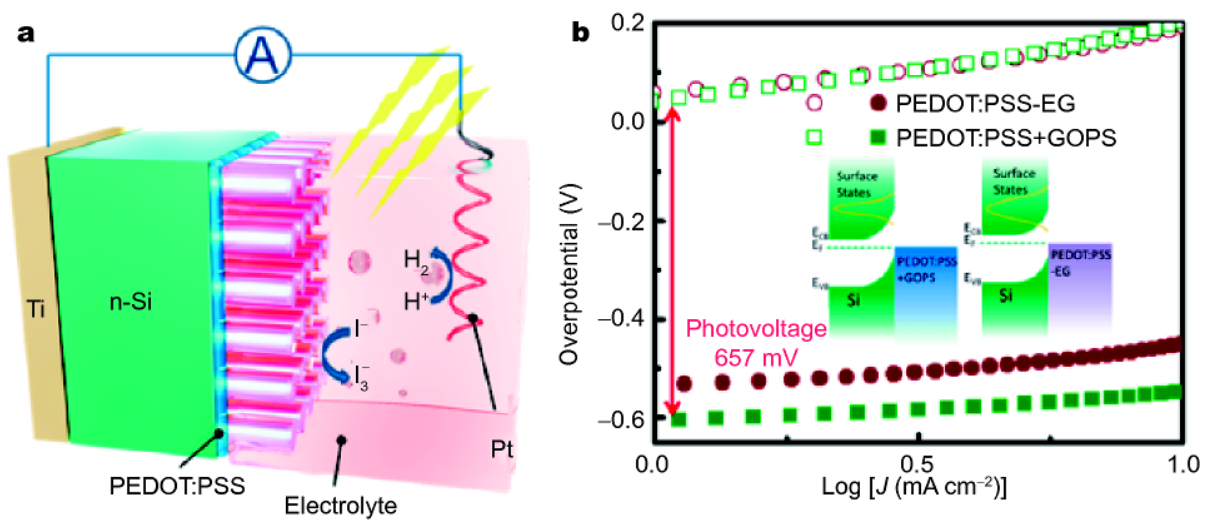

Figure 6 The schematic illustration of PEDOT:PSS modified Si photoelectrode and the corresponding Tafel plot for HI splitting. Reprinted with permission from Ref. [62]. Copyright 2016, American Chemical Society.

still a problem since they are easy to be oxidized by the photogenerated holes due to the thermodynamical instability. More efforts are needed to address this issue before these materials can come into practical use.

\section{Other PEC candidates}

Some other materials such as perovskite and conductive organic polymers also deserve our attention. Their impressive role in solar cell suggests that they have excellent optoelectric properties including light harvest, charge separation and transfer. Taking perovskite as an example, it can harvest light up to $900 \mathrm{~nm}$ and the charge diffusion length can be $\sim 1,000 \mathrm{~nm}$, [58] which endows the perovskite based solar cell a solar conversion efficiency as high as $22.7 \%[59,60]$. But it is so sensitive to water that until now there is no report of using photovoltaic perovskite directing for PEC water splitting. It is believed that a potential way to apply it in PEC is to block perovskite from the direct contact with electrolyte. As for the conductive polymers, such as $\mathrm{P} 3 \mathrm{HT}$ and PEDOT, their band structure is suitable to integrate with some typical semiconductors to realize an organic-inorganic hybrid PEC system [61,62]. Li and coworkers [61] reported that the PEDOT can be coated on the surface of Si arrays for achieving more efficient and stable water oxidation process (Fig. 6). Fumagalli et al. [63] reported another structure based on P3HT and PCBM bulk junction for efficient proton reduction after coating $\mathrm{TiO}_{2}$ on the surface. Despite the success of these examples, the match between inorganic semiconductor and organic polymer remains a great challenge for efficient charge transfer. If the all-organic photoelectrode based on the donor-acceptor bulk junction can be fabricated, it will obtain much more efficient PEC water splitting process.

\section{PHOTOELECTRODE FABRICATION METHODS}

Effective PEC depends not only on elaborate choice of semiconductor but also the suitable route of photoelectrode fabrication. Efficient charge transfer relies on well 


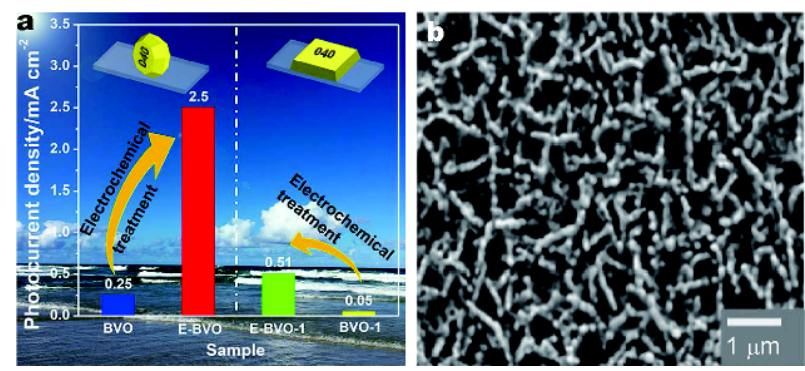

Figure 7 (a) The comparison of photocurrent of $\mathrm{BiVO}_{4}$ photoanode with different proportion of (040) facet exposure and the corresponding electrochemical treated electrodes. Reprinted with permission from Ref. [35]. Copyright 2017, John Wiley \& Sons, Inc. (b) The morphology of porous $\mathrm{BiVO}_{4}$ electrode derived from BiOI nanoplate electrode. Reprinted with permission from Ref. [67]. Copyright 2014, the American Association for the Advancement of Science.

contact between the semiconductor layer and the conductive substrates. Many different methods are developed according to the semiconductor film so as to optimize the contact between semiconductor and substrate. A bottomup method is always desired where the semiconductor film is epitaxially grown on the conductive substrate to minimize the impedance at the interfaces of substrateparticles and particles-particles. But limited by the substrate, a top-down method also will be used for film fabrication with the well-crystallized semiconductor particles. In general, these methods include wet chemical deposition, particle deposition, vapour phase deposition, and so on.

\section{Wet chemical deposition}

Hydrothermal method is a popular way for preparing metal oxide photoelectrode (e.g., $\mathrm{TiO}_{2}, \mathrm{WO}_{3}, \mathrm{BiVO}_{4}$ ) with high degree of crystallization $[28,35,64]$. The morphology of the electrode can be well controlled via adding different capping reagent. For example, Wang et al. [35] reported that the exposed facet of $\mathrm{BiVO}_{4}$ could be depressed when adding polyvinyl pyrrolidone (PVP) during the hydrothermal process. Since the (040) facet is regarded as the oxidative face, the decrease of (040) facet leads to the supressed photoresponse (Fig. 7a). However, hydrothermal deposition is usually time-consumable and of low reproducibility due to the sensitivity to temperature, filling factor, etc.

Alternatively, electrodepositon is also an attractive method since it can facilely control the thickness, morphology and even the phase of the semiconductor via controlling the applied bias, electrolyte $\mathrm{pH}$ and deposition temperature [65,66]. In 2014, Kim et al. [67] reported a facile $\mathrm{BiVO}_{4}$ fabrication method via electrodeposition and calcination to achieve a porous photoelectrode (Fig. $7 b)$. This method is easy to control and repeat, and many exciting results have been reported based on it $[36,68]$.

In addition, the chemical bath method is another widely used method in $\mathrm{FeOOH}, \mathrm{Cu}_{2} \mathrm{O}$, NiOOH deposition $[23,69,70]$. Uniform films can be produced in the stock solution at ambient pressure below boiling point of solution. Similar to the chemical bath method, successive ion layer adsorption (SILA) is frequently used for depositing sulphide based film, such as CdS, $\mathrm{MoS}_{2}$, due to a layer-by-layer alignment of the atoms in these crystal structure [71]. It is a useful strategy in modifying the chalcogenide based semiconductor which shares the same cations with the deposited layer. By controlling the number of deposition layer, the thickness can be easily controlled. Because the reaction occurs at relatively low temperature and ambient pressure, the as-prepared crystal is usually poorly crystallized. Moreover, the metal precursor is required to be stable in stock solution, which limits its application in depositing other films. Other methods, such as spin coating [72], spray pyrolysis [73], can be used to deposit uniform metal oxide film. But they usually lead to compact film with low specific area which is disadvantage for the surface reaction.

\section{Particle deposition}

Particle deposition can be considered as a top-down film deposition method with which the well crystallized semiconductor particles are prepared before being fabricated into photoelectrode with semiconductor films. The most popular method is doctor blading deriving from the research of dye-sensitized solar cell (DSSC) for which the semiconductor paste is spread on the conductive substrate with a spacer to control the film thickness [74]. Usually a following calcination is necessary for removing the organic additives in the paste and strengthening the particles connection. However, the heat treatment is not enough for forming tight crystal linkage and there still 

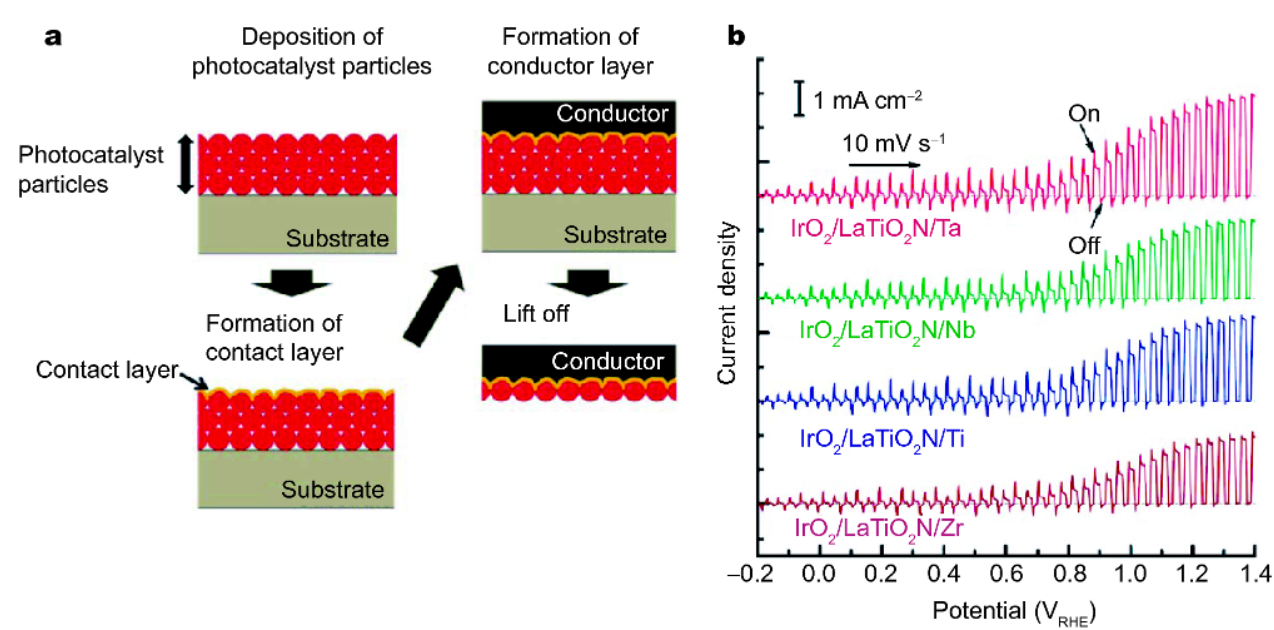

Figure 8 (a) The schematic illustration of particle transfer method. (b) The performance of $\mathrm{LaTiO}_{2} \mathrm{~N}$ photoelectrode with different contact layer. Reprinted with permission from Ref. [75]. Copyright 2013, the Royal Society of Chemistry.

exists abundant grain boundaries that can block the charge transfer. In order to improve the charge transfer process, a following necking treatment can be used to bridge the adjacent particles and provide a path for charge transportation. Wang et al. [18] performed a necking treatment on $\mathrm{Ta}_{3} \mathrm{~N}_{5}$ particulate film fabricated by electrophoresis deposition method, which is another facile electrode fabrication method, and the photocurrent of $\mathrm{Ta}_{3} \mathrm{~N}_{5}$ electrode increased profoundly.

Despite the success in fabricating $\mathrm{Ta}_{3} \mathrm{~N}_{5}$ electrodes by the abovementioned methods, the connection between particles and substrate is too weak to bear harsh mechanical vibration (e.g., ultrasonic wave washing, crash). The particle-transfer method provides a good solution to this problem when the semiconductor particles are coated with a conductive layer before they are peeled off from the undelayed semiconductor film (Fig. 8a) [75]. It is a single crystal layer without particles stacking, so the charge transfer will be very convenient. With this method, the large $\mathrm{LaTiO}_{2} \mathrm{~N}$ particles are able to be fabricated into electrode with high performance (Fig. 8b). However, it should be mentioned that these methods have some limitations: the match between semiconductor and conductive layer is sensitive in determining PEC performance and the Ta contact layer prominently outcompetes the $\mathrm{Zr}$ layer for $\mathrm{LaTiO}_{2} \mathrm{~N}$ photoelelctrode (Fig. 8b). Recently, Li's group [53,54] reported a moisture assisted particulate GaN:ZnO electrode fabrication. It is found that with the presence of moisture, the connection among $\mathrm{GaN}: \mathrm{ZnO}$ particles was prominently enhanced, leading to over 10-time enhancement of the photocurrent compared to the one without moisture treatment. But for the moisture assisted electrode fabrication, it is now only available in the GaN:ZnO semiconductor, more examples are under exploration to extend the application.

\section{Vapour phase deposition}

Films deposited from vapour have been well developed in physics, electronics, and semiconductor industry and the thickness can be controlled at several nanometer. As the most popular one, chemical vapour deposition (CVD) has been used to deposit electrode such as $\mathrm{ZnO}$ [76], $\mathrm{SnS}_{2}$ [77], amorphous Si [78], and so on with well crystallization. The morphology can be well controlled during the CVD by changing the carrier gas, applying catalyst or other parameters. For example, oriented $\mathrm{ZnO}$ nanorod array can be deposited with Au as catalyst by CVD (Fig. 9a) [79]. This method can be used to prepare high quality $\mathrm{ZnO}$ nanowires. Moreover, cauliflower like $\mathrm{Fe}_{2} \mathrm{O}_{3}$ electrode has been reported via an ambient pressured CVD process with Fe-based organic precursor [39]. The materials prepared by CVD usually have high crystallinity, but it is hard to scale up.

Besides CVD, physical vapour deposition (PVD), including magnetron sputtering (MS), pulsed laser deposition (PLD), also have been applied in depositing semiconductor films. As for MS, it works under strong electric field between target and the substrate to allow the plasmonic precursor coating on the conductive layer. Changing the atmosphere (e.g., $\mathrm{O}_{2}, \mathrm{~N}_{2}$ or $\mathrm{NH}_{3}$ ) can produce different metal oxides and nitride, such as $\mathrm{TiO}_{2}$, $\mathrm{WO}_{3}, \mathrm{ZnO}, \mathrm{Ta}_{3} \mathrm{~N}_{5}$, etc. [81-84]. For PLD, it is a top-down film fabrication method where the target is well-prepared semiconductor and the film is formed by depositing the 


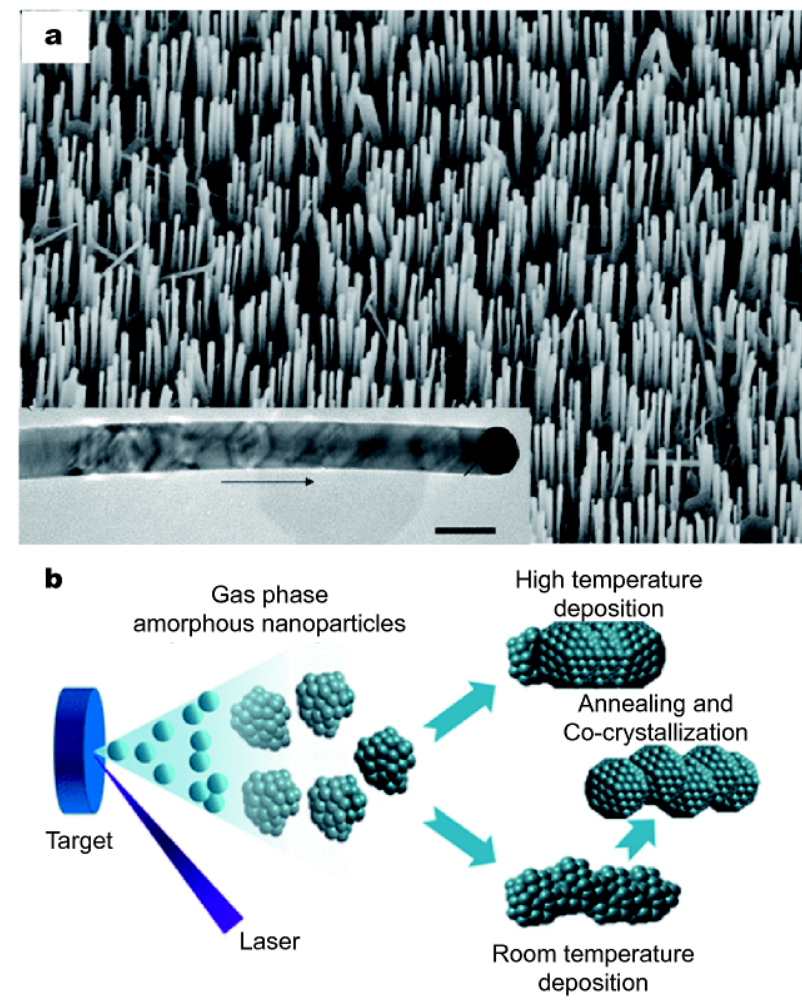

Figure 9 (a) The $\mathrm{ZnO}$ arrays prepared by CVD with gold as calalyst. Reprinted with permission from Ref. [79]. Copyright 2004, American Chemical Society. (b) The schematic illustration of different particle morphology deposited on films by PLD. Reprinted with permission from Ref. [80]. Copyright 2017, American Chemical Society.

tiny particles from the target onto the substrate (Fig. 9b). PLD has less requirement of the conductivity and magnetism of the target; so many candidates such as $\mathrm{CaFe}_{2} \mathrm{O}_{4}$, $\mathrm{SrTiO}_{3}$, etc. have been reported to be used for film fabrication $[85,86]$. In addition, via changing the deposition temperature, it is possible to change the morphology from nanorods (at low temperature) to condensed film (at high temperature) as shown in Fig. 9b [80]. However, these physical vapour deposited films usually face the problem of low rough factor due to the plate-like film, too many defect states due to the abundant crystal stress, and so on. The shadow effect can be used to create an array like morphology and post-heat treatment also be able to release the stress in the film to some degree, but it is still not comparable to the wet-chemical method in the aspect of performance.

\section{Other film deposition method}

Besides the aforementioned methods, some other methods with special advantage also deserve our attention. Flame annealing method is reported by Zheng's group
[87-90]. The as-deposited $\mathrm{TiO}_{2}$ nanotube, $\mathrm{Fe}_{2} \mathrm{O}_{3}$ nanorod, and so on undergo a fast annealing treatment to realize high crystallinity $[87,90]$. Using the annealing method, Han et al. [91] successfully prepared hematite photoelectrode with an onset potential as low as $0.5 \mathrm{~V} v$ s. RHE. Additonally, when adding the precursor source into the flame, it can realize an all-in-one process of particle formation, crystallization and film deposition (Fig. 10a). $\mathrm{MoO}_{3}$ nanobelt (Fig. 10b) and $\mathrm{WO}_{3}$ nanorod film have been fabricated in this way and the derived $\mathrm{WO}_{3} / \mathrm{BiVO}_{4}$ photoanode delivers a photocurrent as high as 3.1 $\mathrm{mA} \mathrm{cm}{ }^{-2}[89,92]$. Molecular beam epitaxy (MBE) is another advanced film fabrication method in preparing film with high quality crystal. Uniform GaN nanorods are deposited on $\mathrm{Si}$ substrate by MBE method and show impressive photocurrent due to the high crystallization of $\mathrm{GaN}$ [93]. But $\mathrm{MBE}$ is an expensive method due to the equipment and the organic metal precursor, which limits its application in PEC.

\section{PEC CHARACTERIZATIONS}

Suitable characterization of the crystal structure, carrier diffusion, surface species, etc. is critical for deeply understanding the PEC process. Many routine technologies have been well applied in PEC research, such as X-ray diffraction (XRD) for phase detection, scanning electron microscopy (SEM) for morphology checking, transmission electron microscope (TEM) for fine structure identifying, and so on. But considering the complex process of water splitting, the above characterization cannot provide a comprehensive insight of the PEC reaction mechanism. Here, some advanced technologies for structure, carrier diffusion and surface reaction characterization in PEC will be briefly summarized.

\section{Structure characterization}

One of the most important things for PEC characterization is to identify the structure contributing to its performance. The X-ray absorption is a very powerful tool in disclosing the local atomic/electronic structure, such as surface distortion, distribution of dopants, defect types, dopant valance and chemical reaction progresses. In the presence of dopants or chemical valance change, the chemical bond will change in terms of the elemental absorption energy or the interatomic distrance [94]. Based on the detected energy range, the X-ray absorption spectrum can be categorized into X-ray absorption nearedge structure (XANES, $30-50 \mathrm{eV}$ above the absorption edge) and extended X-ray absorption fine structure (EXAFS, more than $50 \mathrm{eV}$ above the absorption edge). 

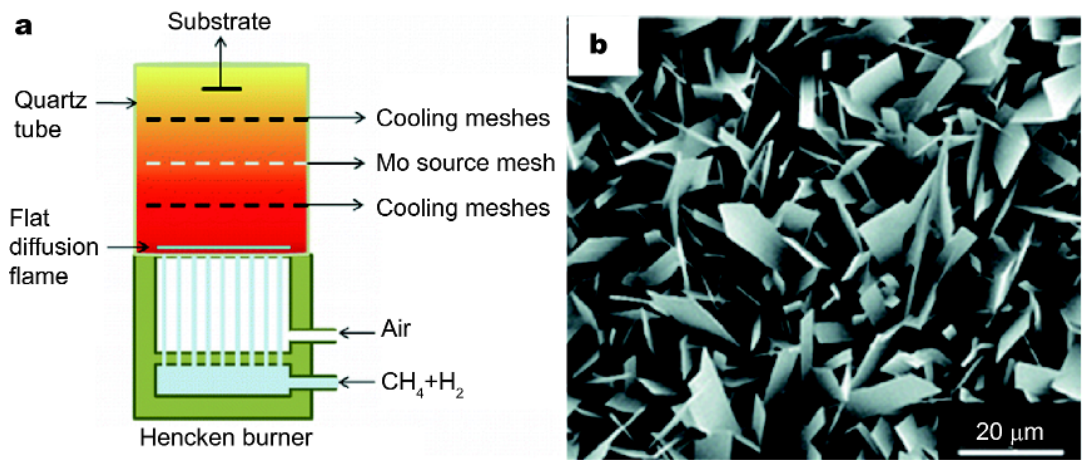

Figure 10 (a) The schematic illustration of equipment used for flame annealing electrode fabrication. (b) The $\mathrm{MoO}_{3}$ nanobelts prepared by flame annealing method. Reprinted with permission from Ref. [92]. Copyright 2011, the American Chemical Society.
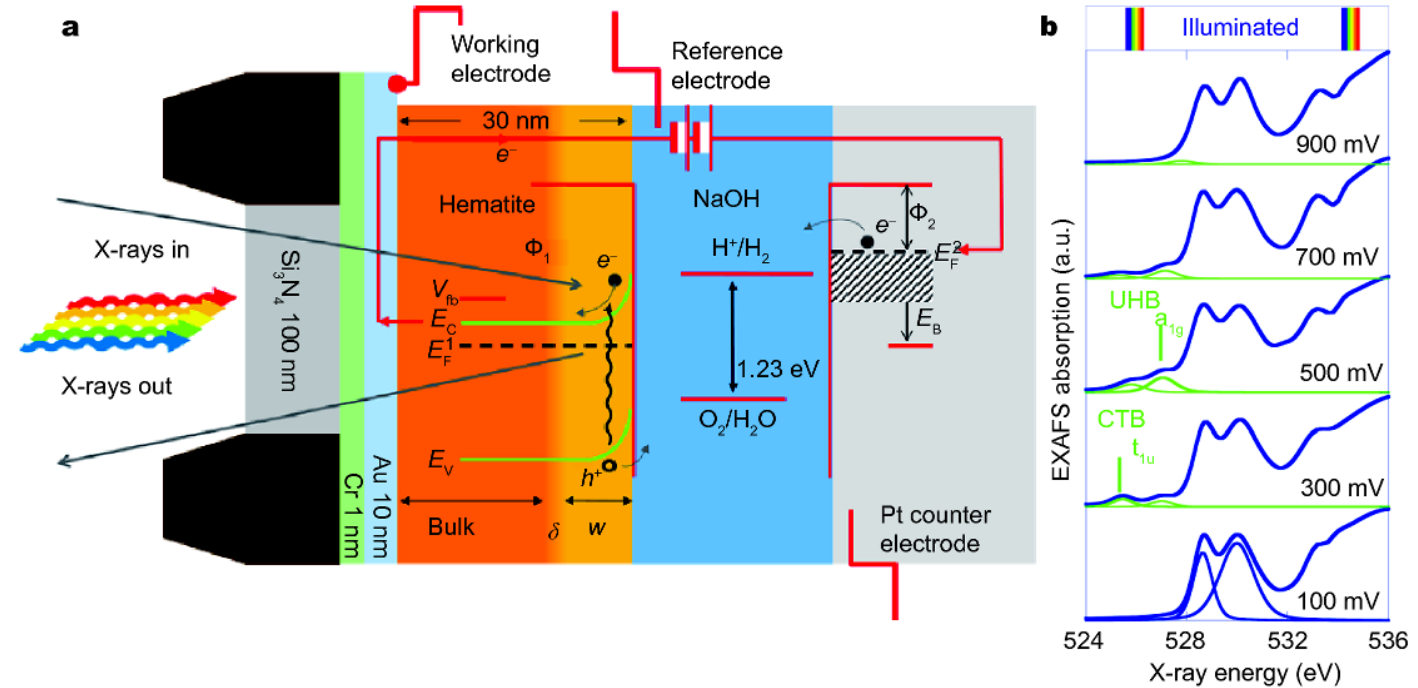

Figure 11 (a) The schematic illustration of in-situ X-ray absorption characterization of hematite electrode. (b) The O 1s EXAFS changes along with different applied bias under illumination. Reprinted with permission from Ref. [95]. Copyright 2012, the American Chemcial Society.

They share the same fundament but have different analysing method. Braun et al. [95] used the EXAFS to study the charge transfer process on hematite electrode and claimed a two-hole accumulation process for PEC water oxidation (Fig. 11). A special PEC cell was designed for the operando X-ray absorption detection (Fig. 11a). And the change of $\mathrm{O}$ 1s EXAFS was claimed as the presence and transfer of photogenerated holes during the biased water oxidation (Fig. 11b). Other researchers focused on the cocatalyst (e.g., $\mathrm{CoPi}, \mathrm{CoO}_{x}$ ) change during the reaction where different chemical states may exist in the compound [96,97]. The X-ray absorption fine structure provides the detail about the metal-oxygen $(\mathrm{M}-\mathrm{O})$ bond and chemical valence change during the reaction. For the $\mathrm{X}$-ray absorption technology, it usually needs a complex data analysis process to gain the reasonable conclusion. So the sophisticated data analysis is important in building the structure-performance relationship.

Besides this, advanced electronic microscope, such as spherical aberration-corrected TEM, can be used to directly observe the structure change. It is very promising to use this technology in visually observing the structure change of the semiconductor or cocatalyst.

\section{Carrier diffusion characterization}

In addition to observing the structure change during the PEC reaction, it is also desired to detect the carrier diffusion process. The photogenerated holes and electrons usually have some characteristic light absorption whose intensity is proportional to the charge carrier's con- 

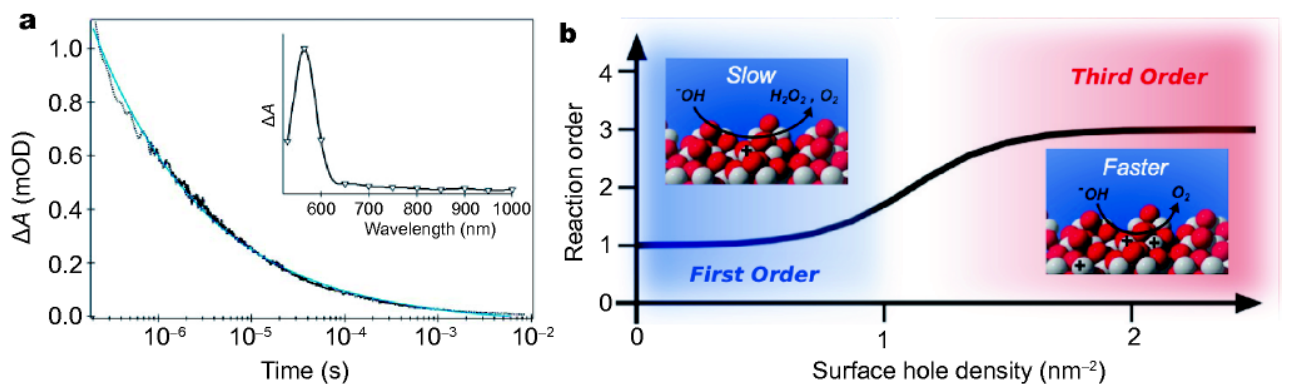

Figure 12 (a) The decay of hole absorption peaked at $580 \mathrm{~nm}$ as illustrated in the inserted pattern. Reprinted with permission from Ref. [98]. Copyright 2013, the Royal Society of Chemistry. (b) The reaction order change along with the surface hole density. Reprinted with permission from Ref. [99]. Copyright 2015, the American Chemical Society.
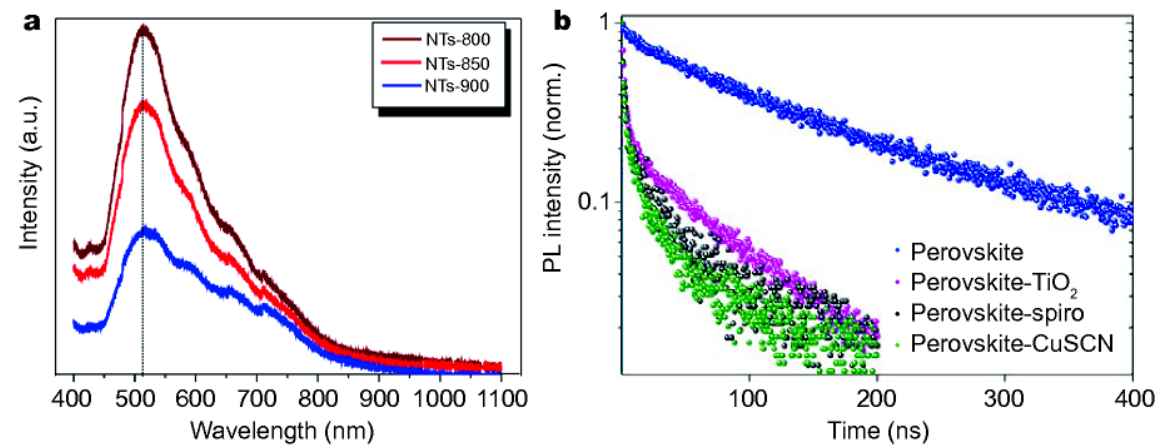

Figure 13 (a) The steady-state PL of $\mathrm{Ta}_{3} \mathrm{~N}_{5}$ photoelectrode calcined at different temperature. Reprinted with permission from Ref. [103]. Copyright 2015, the American Chemical Society. (b) The TPL of perovskite film with different hole transfer layer to quench the PL. Reprinted with permission from Ref. [105]. Copyright 2017, the American Association for the Advancement of Science.

centration. This allows us to trace the carrier decay process with a transient absorption spectrum (TAS) since the amount of charge carriers will decay due to the charge recombination upon the charge production. For example, on hematite based PEC, the absorption at $580 \mathrm{~nm}$ in Fig. $12 \mathrm{a}$ is attributed to the photogenerated holes [98] and further kinetic study indicates that the reaction order changes from 1 under weak light intensity to 3 under strong light intensity (Fig. 12b) [99]. It is also possible to directly observe the absorption from photogenerated electrons via Fourier transform infra-red (FTIR) spectrum considering the very small energy gap among the photogenerated electrons. The time-resolved FTIR has been used to analyze the decay process on photocatalyst such as $\mathrm{TaON}, \mathrm{TiO}_{2}$, and so on $[100,101]$.

Besides direct observing the signal of photocharge, the photoluminescence (PL) process originating from electron-hole recombination can also be used to characterize the charge transfer process. For the steady-state PL, researchers usually hold the point that the lower the PL intensity is, the less the recombination centres will exist
$[102,103]$. It is widely used to characterize the defect state in $\mathrm{Ta}_{3} \mathrm{~N}_{5}$ as demonstrated in Fig. 13a, where Khan et al. [103] attributed the lower PL intensity at higher temperature to the suppressed oxygen defect states. However, this is partially correct only when the recombination occurs via recombination centres rather than from the band-to-band recombination. Moreover, sometimes the light absorption of the semiconductor will decrease because of the shield effect from such as cocatalyst, surface species, and the PL intensity also will decrease due to the reduced pump light intensity, but not the recombination centres amounts. If a pulsed pumping laser is used to excite the PL, it is possible to observe the decay process of PL that is the so called time-resolved PL (TPL). The lifetime derived from TPL can indicate the charge recombination or charge diffusion process according to the test electrode structure $[58,104]$. The results from perovskite solar cell suggest that when the semiconductor film is deposited on insulator substrate (e.g., glass substrate), the fast decay process (short lifetime) usually suggests that there exist a large amount of recombination 

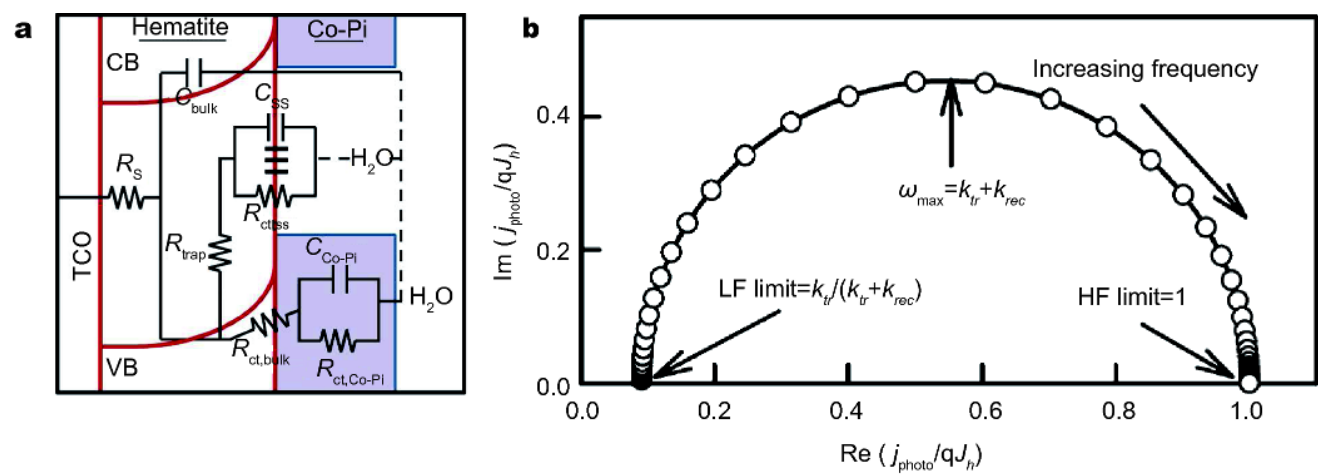

Figure 14 (a) The full equivalent circuit for interpretation of the $\mathrm{Fe}_{2} \mathrm{O}_{3} / \mathrm{CoPi}$ system. Reprinted with permission from Ref. [106]. Copyright 2012, the American Chemical Society. (b) A calculated IMPS response when $k_{\mathrm{rec}}=10 k_{\mathrm{tr}}$. Reprinted with permission from Ref. [108]. Copyright 2013, Springer.

centres. But if the film is deposited on conductive substrate (e.g., FTO or ITO) with the hole or electron transfer materials $\left(\mathrm{TiO}_{2}\right.$, Spiro or CuSCN), the decay path is dominated by drawing the charges with the collector (Fig. 13b) [105]. Therefore, fast TPL decay process indicates fast charge transfer and collection process, which is beneficial to the whole photoelectric process. For the PEC research, the film is usually deposited on conductive substrate. When we try to explain the TPL spectrum, it is necessary to have a full consideration about the experiments fact and more evidences should be provided to support the conclusion derived by TPL or PL.

\section{Reaction characterization}

The above mentioned methods can provide the basic properties of the semiconductor electrode itself regardless of the reaction. To focus on the reaction process, the electrochemical method can be adopted, especially the frequency related methods, such as electrochemical impedance spectroscopy (EIS), intensity-modulated photocurrent spectroscopy (IMPS), which can provide abundant kinetic knowledge.

EIS can be used to analyze the energy loss process in PEC with the assistance of equivalent circuit (EC). Principally, the PEC system is viewed as a black box and many electric elements including resistor $(R)$, capacitor $(C)$, constant phase element (CPE), are used to fabricate the EC for simulating the frequency response of the PEC system. Bisquert's group [106,107] has applied the EIS to analyze the charge transfer on hematite photoanode and emphasized the important role of surface states on surface reaction and charge recombination, and from the result of $\mathrm{Fe}_{2} \mathrm{O}_{3} / \mathrm{CoPi}$ system (Fig. 14a), they pointed out that the holes would accumulate at the electrode-electrolyte interface firstly before the charge consumption happened. Furthermore, IMPS provides an insight into the kinetics of reaction and recombination via measuring the photocurrent under modulated light intensity [108]. Based on the IMPS response, the charge transfer and recombination kinetic constant can be derived from some characteristic frequency (Fig. 14b). By combining EIS with IMPS, it is possible to provide an all-sides view about the charge transfer mechanism and the kinetics which will provide us some guides on how to improve the system one step further.

But the explanation of EIS and IMPS strongly relies on the EC which is not easy to be confirmed without a deep understanding of the charge transfer path of the PEC system. For example, the full equivalent circuit of $\mathrm{Fe}_{2} \mathrm{O}_{3} /$ $\mathrm{CoPi}$ system is too complicate to derive any useful information (Fig. 14a). In order to trace the reaction mechanism, it is important to detect the reaction intermediate in a suitable way. It is highly desired to observe the surface reaction process via an in-situ or operando way since it can provide a direct picture about the structure or chemical states change during reaction. Some operando technologies such as Raman or X-ray photoelectron spectroscopy (XPS) have been applied in thermal- or electro- catalysis research $[109,110]$, but for PEC research, due to the short lifetime and low concentration of the reaction intermediate, the progress in this field is so slow that more effort should be made to move it forward. Some other technologies, such as electron spin resonance (ESR), fluorescent molecular probe, Kelvin probe atomic force microscope (KPFM), also have the potential to be used to investigate the surface species and the surface charge distribution.

It is worth noting that Boettcher's group $[111,112]$ has attempted to investigate the surface species under operation with a dual-working electrode system (Fig. 15). They found that the ion-permeable cocatalyst such as $\mathrm{NiO}_{x}$ could build an adaptive junction with the semi- 
a

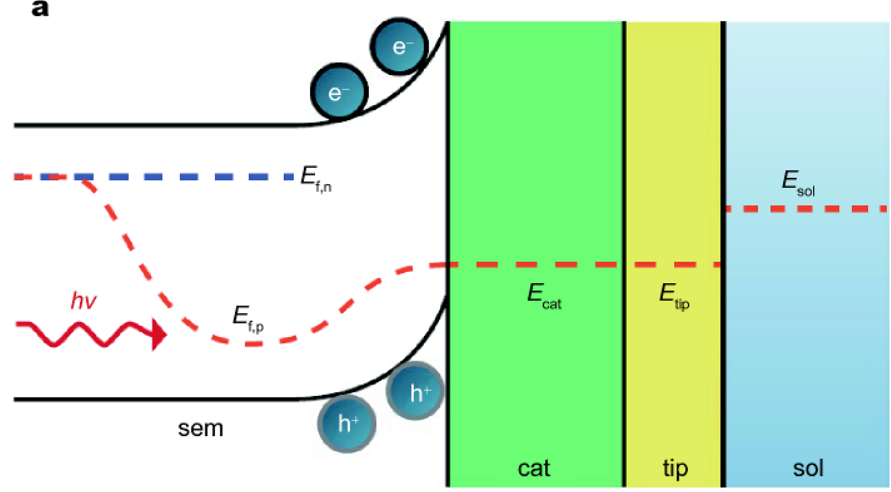

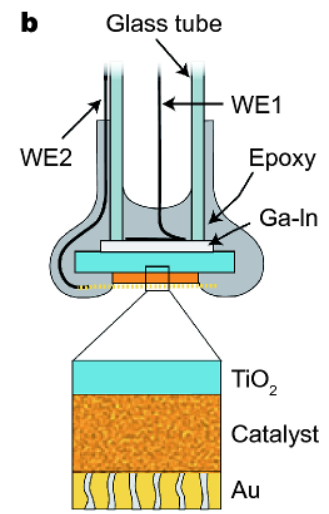

Figure 15 (a) The energy diagram to show the energy level alignment of a dual working electrode system. Reprinted with permission from Ref. [111]. Copyright 2018, Macmillan Publishers Limited. (b) The schematic show of the dual working electrode. Reprinted with permission from Ref. [112]. Copyright 2014, Macmillan Publishers Limited.

conductor which will allow Schottky barrier height changes along with the reaction to realize the optimized charge transfer. This technology can also be used to measure the surface electrochemical potential during operation.

\section{CONCLUSION AND PERSPECTIVE}

In this review, we summarized the recent progress in PEC water splitting in the aspect of materials, electrode fabrication methods and characterization methods. As the building block, the semiconductor materials have been largely expanded to the long-wavelength harvesting candidates. And many advanced electrode fabrication methods have been applied in preparing efficient photoelectrodes. Due to the great effort in recent years, the efficiency of PEC water splitting has a profound progress. For single photoelectrode, the highest applied bias phototo-current efficiency has been over $2.5 \%$ and the nearly theoretical photocurrent of $\mathrm{Ta}_{3} \mathrm{~N}_{5}$ photoelctrode suggests that PEC system can realize the utmost photocurrent under suitable strategies. For integrated system, the solar cell-PEC system has claimed to realize unbiased water splitting with the solar-to-hydrogen efficiency over $10 \%$, which also demonstrated the feasibility of converting solar energy into hydrogen in a high efficiency. At the same time, some operando technologies, including X-ray absorption, transient light-absorption, have been applied to gain deep insight into the PEC reaction process and provide useful guidance for further improvement.

However, it should be mentioned that when taking the efficiency and cost into consideration, no existing system can meet the requirement for practical application. All current PEC systems have some shortages in the aspects of efficiency, stability or cost. Most of the reported highly performed photoelectrodes are fabricated with expensive semiconductor, e.g., GaAs, crystal $\mathrm{Si}$, Ta based semiconductor. By focusing on these prototypical photoelectrodes, we may figure out the criteria for realizing high solar conversion efficiency. It may provide the guidance for further improving the robust and cheap semiconductors such as $\mathrm{Fe}_{2} \mathrm{O}_{3}$. The ideal system is single electrode with highly unbiased solar conversion efficiency since it has the lowest cost. Most of the existing materials cannot fulfil this requirement, so it is expected that the novel materials, such as organic-inorganic perovskite materials, MXene, metal-organic framework (MOF), can be possible to achieve that goals upon modification.

Meanwhile, the characterization technology is expected to have further progress so as to discover the underneath water splitting mechanism that will provide the direction for experimental research to release the bottleneck step and fabricate more effective photoelectrode. It is always desired to achieve a quantitative detection of the PEC system in order to have deep understanding of the photocatalytic process. For this purpose, some pending problems are urgent to be solved: 1) what is the reaction intermediate for PEC reaction, especially during water splitting? 2) How do we evaluate the driving force and overpotential for a PEC reaction? 3) What is the intrinsic role of surface states/cocatalyst during the surface reaction? 4) What does the photogenerated electron/holes experience? To answer all those questions, it requires a high resolution of the time, space and energy during the characterization.

PEC water splitting is a complex process related to materials, engineering, semiconductor physics, and electrochemistry that needs to pay continuous attention in this field. We strongly believe that these efforts will pave 
the path towards a clean and sustainable future of our world.

Received 31 January 2018; accepted 5 March 2018; published online 11 April 2018

1 Perez M, Perez R. Update 2015-A Fundamental Look at Supply Side Energy Reserves for the Planet. IEA-SHCP-Newsletter, 2015

2 Abas N, Kalair A, Khan N. Review of fossil fuels and future energy technologies. Futures, 2015, 69: 31-49

3 Walter MG, Warren EL, McKone JR, et al. Solar water splitting cells. Chem Rev, 2010, 110: 6446-6473

4 McKone JR, Lewis NS, Gray HB. Will solar-driven water-splitting devices see the light of day? Chem Mater, 2014, 26: 407-414

5 Li J, Wu N. Semiconductor-based photocatalysts and photoelectrochemical cells for solar fuel generation: a review. Catal Sci Technol, 2015, 5: 1360-1384

6 Fujishima A, Honda K. Electrochemical photolysis of water at a semiconductor electrode. Nature, 1972, 238: 37-38

7 Wilson RH. Electron transfer processes at the semiconductorelectrolyte interface. Critical Rev Solid State Mater Sci, 1980, 10: $1-41$

8 Gerischer H. The principles of photoelectrochemical energy conversion. In Photovoltaic and Photoelectrochemical Solar Energy Conversion. New York and London: Plenum Press, 1981, 199-261

9 Gerischer H. The impact of semiconductors on the concepts of electrochemistry. Electrochim Acta, 1990, 35: 1677-1699

10 Grätzel M. Photoelectrochemical cells. Nature, 2001, 414: 338344

11 Bella F, Gerbaldi C, Barolo C, et al. Aqueous dye-sensitized solar cells. Chem Soc Rev, 2015, 44: 3431-3473

12 Chen Z, Jaramillo TF, Deutsch TG, et al. Accelerating materials development for photoelectrochemical hydrogen production: Standards for methods, definitions, and reporting protocols. J Mater Res, 2010, 25: 3-16

13 Bonke SA, Wiechen M, MacFarlane DR, et al. Renewable fuels from concentrated solar power: towards practical artificial photosynthesis. Energy Environ Sci, 2015, 8: 2791-2796

14 Chu S, Li W, Yan Y, et al. Roadmap on solar water splitting: current status and future prospects. Nano Futures, 2017, 1: 022001

15 Sivula K, Takata T, van de Krol R. Semiconducting materials for photoelectrochemical energy conversion. Nat Rev Mater, 2016, 1: 15010

16 Chen S, Takata T, Domen K. Particulate photocatalysts for overall water splitting. Nat Rev Mater, 2017, 2: 17050

17 Li X, Wen J, Low J, et al. Design and fabrication of semiconductor photocatalyst for photocatalytic reduction of $\mathrm{CO}_{2}$ to solar fuel. Sci China Mater, 2014, 57: 70-100

18 Wang Z, Qi Y, Ding C, et al. Insight into the charge transfer in particulate $\mathrm{Ta}_{3} \mathrm{~N}_{5}$ photoanode with high photoelectrochemical performance. Chem Sci, 2016, 7: 4391-4399

19 Zhang Z, Yates Jr. JT. Band bending in semiconductors: chemical and physical consequences at surfaces and interfaces. Chem Rev, 2012, 112: 5520-5551

20 Wang L, Sasaki T. Titanium oxide nanosheets: graphene analogues with versatile functionalities. Chem Rev, 2014, 114: 94559486

21 Chen H, Wang Q, Lyu M, et al. Wavelength-switchable photo- current in a hybrid $\mathrm{TiO}_{2}-\mathrm{Ag}$ nanocluster photoelectrode. Chem Commun, 2015, 51: 12072-12075

22 Dotan $\mathrm{H}$, Sivula $\mathrm{K}$, Grätzel $\mathrm{M}$, et al. Probing the photoelectrochemical properties of hematite $\left(\alpha-\mathrm{Fe}_{2} \mathrm{O}_{3}\right)$ electrodes using hydrogen peroxide as a hole scavenger. Energy Environ Sci, 2011, 4: 958-964

23 Wang Z, Liu G, Ding C, et al. Synergetic effect of conjugated $\mathrm{Ni}(\mathrm{OH})_{2} / \mathrm{IrO}_{2}$ cocatalyst on titanium-doped hematite photoanode for solar water splitting. J Phys Chem C, 2015, 119: 19607-19612

24 Soedergren S, Hagfeldt A, Olsson J, et al. Theoretical models for the action spectrum and the current-voltage characteristics of microporous semiconductor films in photoelectrochemical cells. J Phys Chem, 1994, 98: 5552-5556

25 Shinagawa T, Cao Z, Cavallo L, et al. Photophysics and electrochemistry relevant to photocatalytic water splitting involved at solid-electrolyte interfaces. J Energy Chem, 2017, 26: 259-269

26 Salje E, Viswanathan K. Physical properties and phase transitions in $\mathrm{WO}_{3}$. Acta Cryst A, 1975, 31: 356-359

27 Deb SK. Opportunities and challenges in science and technology of $\mathrm{WO}_{3}$ for electrochromic and related applications. Sol Energy Mater Sol Cells, 2008, 92: 245-258

28 Wang S, Chen H, Gao G, et al. Synergistic crystal facet engineering and structural control of $\mathrm{WO}_{3}$ films exhibiting unprecedented photoelectrochemical performance. Nano Energy, 2016, 24: 94-102

29 Weber MF. Efficiency of splitting water with semiconducting photoelectrodes. J Electrochem Soc, 1984, 131: 1258-1265

30 Cardon F, Gomes WP. On the determination of the flat-band potential of a semiconductor in contact with a metal or an electrolyte from the Mott-Schottky plot. J Phys D-Appl Phys, 1978, 11: L63-L67

31 Wolcott A, Smith WA, Kuykendall TR, et al. Photoelectrochemical study of nanostructured $\mathrm{ZnO}$ thin films for hydrogen generation from water splitting. Adv Funct Mater, 2009, 19: 1849-1856

32 Wang $\mathrm{H}$, Lindgren $\mathrm{T}, \mathrm{He} \mathrm{J}$, et al. Photolelectrochemistry of nanostructured $\mathrm{WO}_{3}$ thin film electrodes for water oxidation: mechanism of electron transport. J Phys Chem B, 2000, 104: 5686-5696

33 Maruska HP, Ghosh AK. A study of oxide-based heterostructure photoelectrodes. Sol Energy Mater, 1979, 1: 411-429

34 Kudo A, Omori K, Kato $\mathrm{H}$. A novel aqueous process for preparation of crystal form-controlled and highly crystalline $\mathrm{BiVO}_{4}$ powder from layered vanadates at room temperature and its photocatalytic and photophysical properties. J Am Chem Soc, 1999, 121: 11459-11467

35 Wang S, Chen $\mathrm{P}$, Yun JH, et al. An electrochemically treated $\mathrm{BiVO}_{4}$ photoanode for efficient photoelectrochemical water splitting. Angew Chem, 2017, 129: 8620-8624

36 Kuang Y, Jia Q, Ma G, et al. Ultrastable low-bias water splitting photoanodes via photocorrosion inhibition and in situ catalyst regeneration. Nat Energy, 2017, 2: 16191

37 Sivula K, Le Formal F, Grätzel M. Solar water splitting: progress using hematite $\left(\alpha-\mathrm{Fe}_{2} \mathrm{O}_{3}\right)$ photoelectrodes. ChemSusChem, 2011, 4: $432-449$

38 Bora DK, Braun A, Constable EC. "In rust we trust". Hematite the prospective inorganic backbone for artificial photosynthesis. Energy Environ Sci, 2013, 6: 407-425

39 Tilley S, Cornuz M, Sivula K, et al. Light-induced water splitting with hematite: improved nanostructure and iridium oxide cata- 
lysis. Angew Chem, 2010, 122: 6549-6552

40 Warren SC, Voïtchovsky K, Dotan $\mathrm{H}$, et al. Identifying champion nanostructures for solar water-splitting. Nat Mater, 2013, 12: 842-849

41 Peerakiatkhajohn $\mathrm{P}$, Yun JH, Chen $\mathrm{H}$, et al. Stable hematite nanosheet photoanodes for enhanced photoelectrochemical water splitting. Adv Mater, 2016, 28: 6405-6410

42 Chen S, Wang LW. Thermodynamic oxidation and reduction potentials of photocatalytic semiconductors in aqueous solution. Chem Mater, 2012, 24: 3659-3666

43 Paracchino A, Laporte V, Sivula K, et al. Highly active oxide photocathode for photoelectrochemical water reduction. Nat Mater, 2011, 10: 456-461

$44 \mathrm{Gu}$ J, Yan Y, Krizan JW, et al. p-type $\mathrm{CuRhO}_{2}$ as a self-healing photoelectrode for water reduction under visible light. J Am Chem Soc, 2014, 136: 830-833

45 Hahn NT, Holmberg VC, Korgel BA, et al. Electrochemical synthesis and characterization of $\mathrm{p}-\mathrm{CuBi}_{2} \mathrm{O}_{4}$ thin film photocathodes. J Phys Chem C, 2012, 116: 6459-6466

46 Berglund SP, Abdi FF, Bogdanoff $\mathrm{P}$, et al. Comprehensive evaluation of $\mathrm{CuBi}_{2} \mathrm{O}_{4}$ as a photocathode material for photoelectrochemical water splitting. Chem Mater, 2016, 28: 4231-4242

47 Zhang P, Zhang J, Gong J. Tantalum-based semiconductors for solar water splitting. Chem Soc Rev, 2014, 43: 4395-4422

48 Sun Y, Sun Z, Gao S, et al. All-surface-atomic-metal chalcogenide sheets for high-efficiency visible-light photoelectrochemical water splitting. Adv Energy Mater, 2014, 4: 1300611

49 Chun WJ, Ishikawa $\mathrm{A}$, Fujisawa $\mathrm{H}$, et al. Conduction and valence band positions of $\mathrm{Ta}_{2} \mathrm{O}_{5}, \mathrm{TaON}$, and $\mathrm{Ta}_{3} \mathrm{~N}_{5}$ by UPS and electrochemical methods. J Phys Chem B, 2003, 107: 1798-1803

50 Liu G, Ye S, Yan P, et al. Enabling an integrated tantalum nitride photoanode to approach the theoretical photocurrent limit for solar water splitting. Energy Environ Sci, 2016, 9: 1327-1334

51 Mukherji A, Marschall R, Tanksale A, et al. N-doped CsTaWO ${ }_{6}$ as a new photocatalyst for hydrogen production from water splitting under solar irradiation. Adv Funct Mater, 2011, 21: 126-132

52 Higashi M, Domen K, Abe R. Fabrication of an efficient $\mathrm{BaTaO}_{2} \mathrm{~N}$ photoanode harvesting a wide range of visible light for water splitting. J Am Chem Soc, 2013, 135: 10238-10241

53 Wang Z, Han J, Li Z, et al. Moisture-assisted preparation of compact GaN:ZnO photoanode toward efficient photoelectrochemical water oxidation. Adv Energy Mater, 2016, 6: 1600864

54 Wang Z, Zong X, Gao Y, et al. Promoting charge separation and injection by optimizing the interfaces of GaN:ZnO photoanode for efficient solar water oxidation. ACS Appl Mater Interfaces, 2017, 9: 30696-30702

55 Yokoyama D, Minegishi T, Maeda K, et al. Photoelectrochemical water splitting using a $\mathrm{Cu}(\mathrm{In}, \mathrm{Ga}) \mathrm{Se}_{2}$ thin film. Electrochem Commun, 2010, 12: 851-853

56 Jiang F, Gunawan F, Harada T, et al. $\mathrm{Pt} / \mathrm{In}_{2} \mathrm{~S}_{3} / \mathrm{CdS} / \mathrm{Cu}_{2} \mathrm{ZnSnS}_{4}$ thin film as an efficient and stable photocathode for water reduction under sunlight radiation. J Am Chem Soc, 2015, 137: 13691-13697

57 Lee YL, Chi CF, Liau SY. CdS/CdSe co-sensitized $\mathrm{TiO}_{2}$ photoelectrode for efficient hydrogen generation in a photoelectrochemical cell. Chem Mater, 2009, 22: 922-927

58 Stranks SD, Eperon GE, Grancini G, et al. Electron-hole diffusion lengths exceeding 1 micrometer in an organometal trihalide perovskite absorber. Science, 2013, 342: 341-344

59 Yang WS, Park BW, Jung EH, et al. Iodide management in for- mamidinium-lead-halide-based perovskite layers for efficient solar cells. Science, 2017, 356: 1376-1379

60 Yang WS, Noh JH, Jeon NJ, et al. High-performance photovoltaic perovskite layers fabricated through intramolecular exchange. Science, 2015, 348: 1234-1237

61 Li X, Lu W, Dong W, et al. Si/PEDOT hybrid core/shell nanowire arrays as photoelectrodes for photoelectrochemical water-splitting. Nanoscale, 2013, 5: 5257-5261

62 Cui W, Wu S, Chen F, et al. Silicon/organic heterojunction for photoelectrochemical energy conversion photoanode with a record photovoltage. ACS Nano, 2016, 10: 9411-9419

63 Fumagalli F, Bellani S, Schreier M, et al. Hybrid organic-inorganic $\mathrm{H}_{2}$-evolving photocathodes: understanding the route towards high performance organic photoelectrochemical water splitting. J Mater Chem A, 2016, 4: 2178-2187

64 Zhang D, Yoshida T, Minoura H. Low-temperature fabrication of efficient porous titania photoelectrodes by hydrothermal crystallization at the solid/gas interface. Adv Mater, 2003, 15: 814-817

65 de Jongh PE, Vanmaekelbergh D, Kelly JJ. $\mathrm{Cu}_{2} \mathrm{O}$ : electrodeposition and characterization. Chem Mater, 1999, 11: 3512-3517

66 Siegfried MJ, Choi KS. Elucidating the effect of additives on the growth and stability of $\mathrm{Cu}_{2} \mathrm{O}$ surfaces via shape transformation of pre-grown crystals. J Am Chem Soc, 2006, 128: 10356-10357

67 Kim TW, Choi KS. Nanoporous $\mathrm{BiVO}_{4}$ photoanodes with duallayer oxygen evolution catalysts for solar water splitting. Science, 2014, 343: 990-994

68 Zhong M, Hisatomi T, Kuang Y, et al. Surface modification of $\mathrm{CoO}_{x}$ loaded $\mathrm{BiVO}_{4}$ photoanodes with ultrathin p-type $\mathrm{NiO}$ layers for improved solar water oxidation. J Am Chem Soc, 2015, 137: 5053-5060

69 Pan Q, Wang M, Wang Z. Facile fabrication of $\mathrm{Cu}_{2} \mathrm{O} / \mathrm{CuO}$ nanocomposite films for lithium-ion batteries via chemical bath deposition. Electrochem Solid-State Lett, 2009, 12: A50

$70 \mathrm{Xia} \mathrm{XH}, \mathrm{Tu} \mathrm{JP}$, Zhang J, et al. Electrochromic properties of porous $\mathrm{NiO}$ thin films prepared by a chemical bath deposition. Sol Energy Mater Sol Cells, 2008, 92: 628-633

71 Pathan HM, Lokhande CD. Deposition of metal chalcogenide thin films by successive ionic layer adsorption and reaction (SILAR) method. Bull Mater Sci, 2004, 27: 85-111

72 Souza FL, Lopes KP, Nascente PAP, et al. Nanostructured hematite thin films produced by spin-coating deposition solution: Application in water splitting. Sol Energy Mater Sol Cells, 2009, 93: $362-368$

73 Duret A, Grätzel M. Visible light-induced water oxidation on mesoscopic $\alpha-\mathrm{Fe}_{2} \mathrm{O}_{3}$ films made by ultrasonic spray pyrolysis. J Phys Chem B, 2005, 109: 17184-17191

74 Ding IK, Melas-Kyriazi J, Cevey-Ha NL, et al. Deposition of holetransport materials in solid-state dye-sensitized solar cells by doctor-blading. Org Electron, 2010, 11: 1217-1222

75 Minegishi T, Nishimura N, Kubota J, et al. Photoelectrochemical properties of $\mathrm{LaTiO}_{2} \mathrm{~N}$ electrodes prepared by particle transfer for sunlight-driven water splitting. Chem Sci, 2013, 4: 1120-1124

76 Chang PC, Fan Z, Wang D, et al. ZnO nanowires synthesized by vapor trapping CVD method. Chem Mater, 2004, 16: 5133-5137

77 Chen H, Lyu M, Zhang M, et al. Switched photocurrent on tin sulfide-based nanoplate photoelectrodes. ChemSusChem, 2017, 10: $670-674$

78 Izu M, Ellison T. Roll-to-roll manufacturing of amorphous silicon alloy solar cells with in situ cell performance diagnostics. Sol Energy Mater Sol Cells, 2003, 78: 613-626 
79 Wang X, Summers CJ, Wang ZL. Large-scale hexagonal-patterned growth of aligned $\mathrm{ZnO}$ nanorods for nano-optoelectronics and nanosensor arrays. Nano Lett, 2004, 4: 423-426

80 Mahjouri-Samani M, Tian M, Puretzky AA, et al. Nonequilibrium synthesis of $\mathrm{TiO}_{2}$ nanoparticle "building blocks" for crystal growth by sequential attachment in pulsed laser deposition. Nano Lett, 2017, 17: 4624-4633

81 Li A, Wang $\mathrm{Z}$, Yin $\mathrm{H}$, et al. Understanding the anatase-rutile phase junction in charge separation and transfer in a $\mathrm{TiO}_{2}$ electrode for photoelectrochemical water splitting. Chem Sci, 2016, 7: 6076-6082

82 Vidyarthi VS, Hofmann M, Savan A, et al. Enhanced photoelectrochemical properties of $\mathrm{WO}_{3}$ thin films fabricated by reactive magnetron sputtering. Int J Hydrogen Energy, 2011, 36: 4724-4731

83 Carcia PF, McLean RS, Reilly MH, et al. Transparent ZnO thinfilm transistor fabricated by RF magnetron sputtering. Appl Phys Lett, 2003, 82: 1117-1119

84 Yokoyama D, Hashiguchi $\mathrm{H}$, Maeda $\mathrm{K}$, et al. $\mathrm{Ta}_{3} \mathrm{~N}_{5}$ photoanodes for water splitting prepared by sputtering. Thin Solid Films, 2011, 519: 2087-2092

85 Cao J, Kako T, Li P, et al. Fabrication of p-type $\mathrm{CaFe}_{2} \mathrm{O}_{4}$ nanofilms for photoelectrochemical hydrogen generation. Electrochem Commun, 2011, 13: 275-278

86 Sangle AL, Singh S, Jian J, et al. Very high surface area mesoporous thin films of $\mathrm{SrTiO}_{3}$ grown by pulsed laser deposition and application to efficient photoelectrochemical water splitting. Nano Lett, 2016, 16: 7338-7345

87 Cho IS, Logar M, Lee CH, et al. Rapid and controllable flame reduction of $\mathrm{TiO}_{2}$ nanowires for enhanced solar water-splitting. Nano Lett, 2013, 14: 24-31

88 Feng Y, Cho IS, Rao PM, et al. Sol-flame synthesis: a general strategy to decorate nanowires with metal oxide/noble metal nanoparticles. Nano Lett, 2012, 13: 855-860

89 Rao PM, Cai L, Liu C, et al. Simultaneously efficient light absorption and charge separation in $\mathrm{WO}_{3} / \mathrm{BiVO}_{4}$ core/shell nanowire photoanode for photoelectrochemical water oxidation. Nano Lett, 2014, 14: 1099-1105

90 Rao PM, Zheng X. Rapid catalyst-free flame synthesis of dense, aligned $\alpha-\mathrm{Fe}_{2} \mathrm{O}_{3}$ nanoflake and $\mathrm{CuO}$ nanoneedle arrays. Nano Lett, 2009, 9: 3001-3006

91 Han J, Zong X, Wang Z, et al. A hematite photoanode with gradient structure shows an unprecedentedly low onset potential for photoelectrochemical water oxidation. Phys Chem Chem Phys, 2014, 16: 23544-23548

92 Cai L, Rao PM, Zheng X. Morphology-controlled flame synthesis of single, branched, and flower-like $\alpha-\mathrm{MoO}_{3}$ nanobelt arrays. Nano Lett, 2011, 11: 872-877

93 AlOtaibi B, Harati M, Fan S, et al. High efficiency photoelectrochemical water splitting and hydrogen generation using GaN nanowire photoelectrode. Nanotechnology, 2013, 24: 175401

94 Sun Z, Liu Q, Yao T, et al. X-ray absorption fine structure spectroscopy in nanomaterials. Sci China Mater, 2015, 58: 313341

95 Braun A, Sivula K, Bora DK, et al. Direct observation of two electron holes in a hematite photoanode during photoelectrochemical water splitting. J Phys Chem C, 2012, 116: 1687016875

96 Kanan MW, Yano J, Surendranath Y, et al. Structure and valency of a cobalt-phosphate water oxidation catalyst determined by in situ X-ray spectroscopy. J Am Chem Soc, 2010, 132: 13692-13701 97 González-Flores D, Sánchez I, Zaharieva I, et al. Heterogeneous water oxidation: surface activity versus amorphization activation in cobalt phosphate catalysts. Angew Chem Int Ed, 2015, 54: 2472-2476

98 Barroso M, Pendlebury SR, Cowan AJ, et al. Charge carrier trapping, recombination and transfer in hematite $\left(\alpha-\mathrm{Fe}_{2} \mathrm{O}_{3}\right)$ water splitting photoanodes. Chem Sci, 2013, 4: 2724-2734

99 le Formal F, Pastor E, Tilley SD, et al. Rate law analysis of water oxidation on a hematite surface. J Am Chem Soc, 2015, 137: 6629-6637

100 Chen S, Qi Y, Hisatomi T, et al. Efficient visible-light-driven Zscheme overall water splitting using a $\mathrm{MgTa}_{2} \mathrm{O}_{6-x} \mathrm{~N}_{y} / \mathrm{TaON}$ heterostructure photocatalyst for $\mathrm{H}_{2}$ evolution. Angew Chem Int Ed, 2015, 54: 8498-8501

101 Su W, Zhang J, Feng Z, et al. Surface phases of $\mathrm{TiO}_{2}$ nanoparticles studied by UV Raman spectroscopy and FT-IR spectroscopy. J Phys Chem C, 2008, 112: 7710-7716

102 Fu G, Yan S, Yu T, et al. Oxygen related recombination defects in $\mathrm{Ta}_{3} \mathrm{~N}_{5}$ water splitting photoanode. Appl Phys Lett, 2015, 107: 171902

103 Khan S, Zapata MJM, Baptista DL, et al. Effect of oxygen content on the photoelectrochemical activity of crystallographically preferred oriented porous $\mathrm{Ta}_{3} \mathrm{~N}_{5}$ nanotubes. J Phys Chem C, 2015, 119: 19906-19914

104 Xing G, Mathews N, Sun S, et al. Long-range balanced electronand hole-transport lengths in organic-inorganic $\mathrm{CH}_{3} \mathrm{NH}_{3} \mathrm{PbI}_{3}$. Science, 2013, 342: 344-347

105 Arora N, Dar MI, Hinderhofer A, et al. Perovskite solar cells with CuSCN hole extraction layers yield stabilized efficiencies greater than 20\%. Science, 2017, 358: 768-771

106 Klahr B, Gimenez S, Fabregat-Santiago F, et al. Photoelectrochemical and impedance spectroscopic investigation of water oxidation with "Co-Pi"-coated hematite electrodes. J Am Chem Soc, 2012, 134: 16693-16700

107 Klahr B, Gimenez S, Fabregat-Santiago F, et al. Water oxidation at hematite photoelectrodes: the role of surface states. J Am Chem Soc, 2012, 134: 4294-4302

108 Peter LM. Energetics and kinetics of light-driven oxygen evolution at semiconductor electrodes: the example of hematite. J Solid State Electrochem, 2013, 17: 315-326

109 Deng Y, Ting LRL, Neo PHL, et al. Operando Raman spectroscopy of amorphous molybdenum sulfide $\left(\mathrm{MoS}_{x}\right)$ during the electrochemical hydrogen evolution reaction: identification of sulfur atoms as catalytically active sites for $\mathrm{H}^{+}$reduction. ACS Catal, 2016, 6: 7790-7798

110 Velu S, Suzuki K, Vijayaraj M, et al. In situ XPS investigations of $\mathrm{Cu}_{1-x} \mathrm{Ni}_{x} \mathrm{ZnAl}$-mixed metal oxide catalysts used in the oxidative steam reforming of bio-ethanol. Appl Catal B-Environ, 2005, 55: 287-299

111 Nellist MR, Laskowski FAL, Qiu J, et al. Potential-sensing electrochemical atomic force microscopy for in operando analysis of water-splitting catalysts and interfaces. Nat Energy, 2018, 3: 4652

112 Lin F, Boettcher SW. Adaptive semiconductor/electrocatalyst junctions in water-splitting photoanodes. Nat Mater, 2014, 13: $81-86$

Acknowledgements This work is supported by the Australian Research Council through its Discovery Project (DP) and Federation Fel- 
lowship (FF) Program. The Queensland node of the Australian National Fabrication Facility (ANFF) is also appreciated.

Author contributions

Wang $\mathrm{L}$ initiated and guided the whole work.
Wang $\mathrm{Z}$ surveyed the literature, wrote the manuscript and discussed with Wang L.

Conflict of interest The authors declare no conflict of interest.
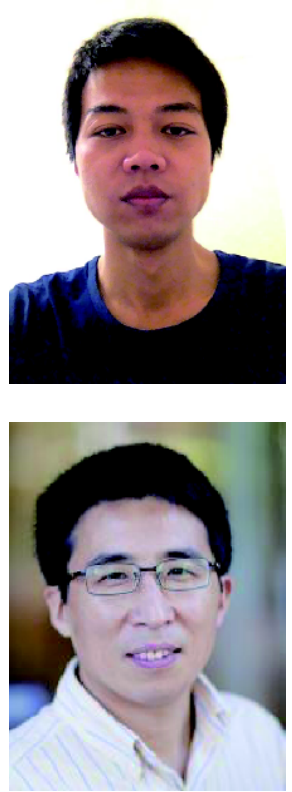

Zhiliang Wang received his $\mathrm{PhD}$ degree (supervised by Prof. Can Li) in physical chemistry from Dalian Institute of Chemical Physics (DICP), Chinese Academy of Sciences in 2017 and now he works in Prof. Wang's group as a postdoctoral fellow at The University of Queensland (UQ), Australia. His current research focuses on photoelectrochemical solar energy conversion.
Lianzhou Wang is a professor at the School of Chemical Engineering and the director of Nanomaterials Center, UQ, Australia. He received his PhD degree from the Chinese Academy of Sciences in 1999. Before joining UQ in 2004, he worked at two National Institutes (NIMS and AIST) of Japan for five years. Wang's research interests mainly focus on the design and application of semiconducting nanomaterials in renewable energy conversion/storage systems, including photocatalysis, solar cell, rechargable batteries and so on.

\section{光电催化分解水: 电极材料, 电极组装和电极表征}

\section{王志亮, 王连洲}

摘要 光电催化分解水作为一种清洁可持续获取氢能的技术吸引了人们的广泛关注. 高效光电过程有赖于选择合适的半导体材料, 即: 具 有较小的带隙以保障足够的光吸收; 优异的电荷分离以保障光生电荷向反应位点的迁移; 高效的表面催化能力以实现对光生电荷的充分 利用. 同时, 合理的电极组装方法对于电荷的迁移与表面反应也起到至关重要的作用. 进一步, 强有力的表征技术为深入了解光电催化分 解水的过程, 认清反应限速步骤并据此进一步优化电极设计提供了保证和依据. 本文着眼于实现高效的光催化分解水制氢过程, 综述了电 极材料的开发, 电极组装手段和光电催化表征技术这三个方面的研究进展, 并期望为发展更加高效的光电催化分解水过程提供指导. 